\begin{tabular}{c|c|c}
\hline JURNAL PENELITIAN FARMASI HERBAL & VOL. 1 NO. 2 & $\begin{array}{c}\text { EDITION: NOVEMBER 2018 - } \\
\text { APRIL 2019 }\end{array}$ \\
\hline & http://ejournal.delihusada.ac.id/index.php/JPFH & \\
\cline { 2 - 3 } RECEIVED: 17 FEBRUARI 2019 & REVISED: 18 MARET 2019 & ACCEPTED: 21 APRIL 2019 \\
\hline
\end{tabular}

\title{
IDENTIFIKASI KADAR GLUKOSA DAN SUKROSA PADA MADU HUTAN
}

\author{
Zuhairiah Nst, Ernala Br Ginting, Dyna Grace Romatua, Firdaus Fahdi \\ Universitas Sari Mutiara Indonesia, Jl. Kapten Muslin No. 79 Helvetia Medan \\ Email :zuhairiahnasution@gmail.com
}

\begin{abstract}
Glucose and sucrose tests are performed as one of honey's standard quality. Meanwhile the process of honey production by bees itself is a complex process, so there is a high probability of differences in the levels and composition of glucose and sucrose among the types of honey circulating in the community. The composition of glucose and sucrose of each honey can affect its efficacy mainly when it is used for treatment process. The aim of this research is to know glucose and sucrose level in forest honey and compare it with honey's standard quality according to Indonesian national standard (SNI 01-3545-2013). The samples were 3 forest honey from different village. Sample $A$ is forest honey from Kubu Simbelang Village, Sample B from Bunuraya Village, and Sample C from Suka Village, Tigapanah District. The determination of glucose and sucrose levels was performed by Luff Schoorl method. The result of this study was glucose average level of each sample $A, B$ and $C$ is $71,42 \%, 66,24 \%$, and $71,21 \%$. The sucrose average levels of sample $A, B$, and $C$ is 3,09\%, 4,51, and 3,04\%. It can be stated that all forest honey used in this study has fulfilled the requirements according to SNI 01-3545-2013 which set that glucose level of honey must be at least 65\% while the sucrose level is maximum 5\%.
\end{abstract}

Keywords: Glucose, Sucrose, Luff Schoorl

\section{PENDAHULUAN}

Madu adalah salah satu pemanis alami yang biasa dikonsumsi oleh manusia sebagai pengganti gula. Madu berwujud seperti sirup, namun lebih kental dan memiliki rasa yang manis. Madu merupakan pemanis alami yang dihasilkan dari bahan baku nektar bunga. Madu memilki rasa manis yang berbeda dari gula atau pemanis lainnya, sehingga membuat orang lain lebih menyukainya dari pada gula atau pemanis lainnya. Selain itu, madu diklaim memiliki kandungan nutrisi lain yang berguna bagi kesehatan sehingga menjadi bahan makanan favorit bagi banyak orang.

Menurut Standar Nasional Indonesia (SNI) 013545-2013, madu adalah cairan alami yang umumnya mempunyai rasa manis yang dihasilkan oleh lebah madu (Apis Sp.) dari sari bunga tanaman (floral nektar) atau bagian lain dari tanaman (ekstra floral).

Madu merupakan bahan makanan sumber energi yang sangat baik karena madu mengandung gula-gula sederhana yang dapat segera dimanfaatkan tubuh, serta mengandung garam-garam mineral dan bahan-bahan lain yang sangat berguna bagi tubuh. Selain itu, hanya madu bahan makanan yang mengandung gulayang tidak memerlukan pengolahan lebih dahulu untuk dimanfaatkan oleh manusia (Sihombing, 1997).

Manfaat madu sangat banyak dan beragam, salah satunya dalam pengobatan. Berawal dari penemuan Hippocrates yang telah 
http://ejournal.delihusada.ac.id/index.php/JPFH

berhasil memanfaatkan madu sebagai obat dalam penyembuhan luka, dan semenjak hal tersebut penggunaan dan manfaat madu berkembang mengingat kandungan madu yang sebagian besar terdiri dari karbohidrat jenis monosakarida yaitu seperti glukosa dan banyak digunakan dalam obat untuk penyembuhan bermacam-macam penyakit, seperti : Kardiovaskular, pendarahan perut, ulser perut, penyakit pencernaan, penyakit untuk para penderita keracunan (Sumoprastowo dan Suprapto, 1993).

Madu hutan adalah madu yang dihasilkan dari lebah Apis mellifera yang mencari makan dari bunga-bunga tanaman dihutan dan membentuk sarangnya didahan-dahan pepohonan hutan. Bentuk madu merupakan cairan kental seperti sirup, berwarna bening atau kekuningan pucat samapai cokelat kekuningan. Memiliki rasa yang khas yaitu manis dengan aroma yang enak dan segar. Jika dipanaskan, aromanya menjadi lebih kuat tetapi bentuknya tak berubah (Sarwono, 2001).

Dalam Farmakope Indonesia edisi V dijelaskan bahwa madu murni adalah madu yang diperoleh dari sarang lebah Apis mellifera dan spesies lainnya yang telah dimurnikan dengan pemanasan $70^{\circ} \mathrm{C}$. Setelah dingin, kotoran yang mengapung disaring. Selanjutnya, madu dapat ditambahkan dengan air secukupnya untuk pengenceran sehingga bobot madu memenuhi persyaratan.

Syarat mutu madu salah satunya adalah kandungan glukosa dan sukrosanya yaitu minimal $65 \%$ untuk glukosa dan maksimal 5\% untuk sukrosa. Sementara itu proses produksi madu oleh lebah itu sendiri merupakan proses yang kompleks, sehingga kemungkinan besar terjadi perbedaan kadar dan komposisi glukosa dan sukrosa antara madu yang satu dan lainnya. Perbedaan Komposisi glukosa dan sukrosa tiap-tiap madu dapat mempengaruhi khasiatnya (Winarno, 1981).

Menurut Sihombing (1997), zat-zat atau senyawa yang terkandung dalam madu sangat kompleks dan kini telah diketahui tidak kurang dari 181 macam zat atau senyawa dalam madu dan dapat terus bertambah dengan dilakukannya penelitian-penelitian lain di masa yang akan datang. Komposisi madu ditentukan oleh dua faktor utama yakni komposisi nektar asal madu bersangkutan dan faktor-faktor eksternal tertentu seperti cuaca, suhu dan termasuk juga cara pengambilan madu dari sarangnya.

Berdasarkan perolehannya, madu dapat diperoleh dari hasil budidaya lebah atau dari lebah liar sehingga sering disebut madu ternak dan madu hutan.Madu hutan, yaitu madu yang dihasilkan dan diambil langsung dari sarang lebah yang terdapat di pohonpohon dalam hutan (Dharmestiwi, 2007).

Metode Luff Schoorl merupakan suatu cara penentuan monosakarida secara kimia. Pada penentuan metode ini, yang ditentukan adalah Kuprioksida dalam larutan sebelum direaksikan dengan gula pereduksi (titrasi blanko) dan sesudah direaksikan dengan sampel gula reduksi (titrasi sampel). Reaksi yang terjadi pada penentuan gula dengan cara ini mula-mula Kuprooksida yang ada di dalam reagen akan membebaskan iod dari garam kalium iodida. Banyaknya iod yang dibebaskan ekivalen dengan banyaknya Kuprioksida. Banyaknya iod dapat diketahui dengan titrasi dengan menggunakan Natrium tiosulfat. Untuk menentukan titik akhir titrasi maka diperlukan Indikator amilum. Titik akhir titrasi ditandai dengan perubahan warna larutan dari yang awalnya berwarna biru menjadi putih (Sudarmadji, 1996).

Reaksi yang terjadi dalam penentuan gula dengan metode Luff Scoorl sebagai berikut:

$$
\begin{array}{rr}
\mathrm{R}-\mathrm{COH}+\mathrm{Cu}_{2} \mathrm{O} \rightarrow & \mathrm{R}-\mathrm{COOH} \\
\mathrm{H}_{2} \mathrm{SO}_{4}+\mathrm{Cu}_{2} \mathrm{O} \rightarrow \mathrm{CuSO}_{4}+\mathrm{H}_{2} \mathrm{O} \\
\mathrm{CuSO}_{4}+2 \mathrm{KI} \rightarrow & \mathrm{C}_{\mathrm{u}} \mathrm{I}_{2}+\mathrm{I}_{2} \\
2 \mathrm{C}_{\mathrm{u}} \mathrm{I}_{2} \rightarrow & \mathrm{C}_{\mathrm{u}} \mathrm{I}_{2}+\mathrm{I}_{2} \\
\mathrm{I}_{2}+\mathrm{Na}_{2} \mathrm{~S}_{2} \mathrm{O}_{3} \rightarrow \mathrm{Na}_{2} \mathrm{~S}_{4} \mathrm{O}_{6}+\mathrm{NaI} \\
\mathrm{I}_{2}+\text { amilum } \rightarrow & \text { Biru }
\end{array}
$$

(Sudarmadji, 1996). 
Penelitian ini bertujuan untuk mengetahui kadar glukosa dan sukrosa pada Madu Hutan dan mengetahui apakah kadar glukosa dan sukrosa sesuai dengan Standar Nasional Indonesia (SNI01-3545-2013).

\section{METODE}

Penetapan kadar glukosa dan sukrosa pada madu dilakukan dengan metode Luff schoorl. Sampel yang digunakan adalah madu hutan asli yang diambil dari tiga desa yang berbeda yaitu desa Kubu Simbelang, desa Bunuraya, desa Suka kecamatan Tiga panah Kabupaten Karo Sumatera Utara.

\section{Alat dan bahan}

Alat yang digunakan dalam penelitian ini adalah alat-alat gelas, buret $50 \mathrm{ml}$, labu alas bulat, neraca analitik, labu ukur $100 \mathrm{ml}$ dan $250 \mathrm{ml}$, pemanas listrik, pipet volumetrik 10 $\mathrm{ml}, 25 \mathrm{ml}$ dan $50 \mathrm{ml}$, termometer, stopwatch.

Bahan yang digunakan dalam penelitian ini adalah Larutan Kanji 0,5\%, Larutan $\mathrm{H}_{2} \mathrm{SO}_{4}$ $25 \%$, Larutan $\mathrm{KI} 20 \%$, Larutan $\left(\mathrm{NH}_{4}\right)_{2} \mathrm{HPO} 4$ $10 \%$, Larutan $\mathrm{Na}_{2} \mathrm{~S}_{2} \mathrm{O}_{3} 0,1 \mathrm{~N}$, Larutan Timbal Asetat setengah basa, dan Larutan Luff Schoorl.

\section{Pembuatan Larutan Sampel}

Sebanyak 2 g sampel dimasukkan kedalam labu ukur $250 \mathrm{ml}$ lalu ditambahkan air suling dan digoyang. Ditambahkan $5 \mathrm{ml}$ larutan Timbal asetat setengah basa dan digoyang, diteteskan tetes demi tetes larutan $\left(\mathrm{NH}_{4}\right)_{2} \mathrm{HPO}_{4} \quad 10 \%$ hingga terbentuk endapan putih. Setelah itu labu ukur digoyang dan ditepatkan isi labu ukur sampai garis tanda dengan air suling, lalu dikocok $12 \times 12$, didiamkan dan disaring. Filtrat yang diperoleh digunakan sebagai larutan sampel dalam penetapan kadar glukosa dan sukrosa.

\section{Penetapan Kadar Glukosa}

Dipipet $10 \mathrm{ml}$ larutan sampel dan dimasukkan kedalam labu didih. Larutan sampel ditambahkan $15 \mathrm{ml}$ air suling dan $25 \mathrm{ml}$ larutan Luff Schoorl serta beberapa butir batu didih, setelah itu dihubungkan dengan pendingin tegak, dipanaskan di atas pemanas listrik, dan usahakan dalam waktu 3 menit harus sudah mulai mendidih, dipanaskan terus selama 10 menit. Kemudian labu didih diangkat dan segera didinginkan dengan aliran air. Kemudian tambahkan $10 \mathrm{ml}$ larutan KI $20 \%$, larutan $\mathrm{H}_{2} \mathrm{SO}_{4} 25 \%$ dengan hati-hati kedalam labu didih. Kemudian lakukan titrasi dengan larutan Natrium tiosulfat $0,1 \mathrm{~N}$ dan ditambahkan larutan kanji $0,5 \%$ sebagai indikator. Kerjakan penentapan blanko dengan $25 \mathrm{ml}$ air dan $25 \mathrm{ml}$ larutan Lufft Schoorl.(SNI-2892-1992).

\section{Penetapan Kadar Sukrosa}

Dipipet $50 \mathrm{ml}$ larutan sampel ke dalam labu didih kemudian tambahkan $25 \mathrm{ml} \mathrm{HCl} 25 \%$ pasang termometer dan lakukan hidrolisis di atas penangas Air. Apabila suhu mencapai 68$70^{\circ} \mathrm{C}$ suhu dipertahankan 10 menit tepat, Angkat dan bilas termometer dengan air lalu dinginkan. Kedalam labu didih ditambahkan $\mathrm{NaOH}$ 30\% Sampai netral (warna merah jambu) dengan indikator fenoftalein, Tepatkan sampai tanda tera dengan air suling kocok 12 kali maka diperoleh larutan hasil hidrolisis sampel.

Larutan hasil hidrolisis dipipet $10 \mathrm{ml}$ dan masukkan kedalam labu didih. Tambahkan 15 $\mathrm{ml}$ air suling dan $25 \mathrm{ml}$ larutan Luff serta beberapa butir batu didih, Hubungkan labu didih dengan pendingin tegak dan panaskan diatas penangas listrik, Usahakan dalam waktu 3 menit sudah harus mulai mendidih. Panaskan terus selama 10 menit. Angkat dan segera dinginkan dengan air mengalir. Setelah dingin tambahkan $10 \mathrm{ml}$ larutan $\mathrm{KI} 20 \%$ dan $25 \mathrm{ml} \mathrm{H} \mathrm{SO}_{4} \quad 25 \%$ dengan hati-hati. Lalu titrasi dengan larutan Natrium Tiosulfat $\left(\mathrm{Na}_{2} \mathrm{~S}_{2} \mathrm{O}_{3}\right)$ dari warna kuning gading sampai putih susu dengan larutan kanji 0,5\% sebagai indikator, Lakukan juga penetapan blanko dengan $25 \mathrm{ml}$ larutan Luff, kerjakan seperti diatas ( $V_{2} \mathrm{ml}$ ) (SNI-2892-1992).

\section{Interprestasi Hasil}

(V2-V1) ml tio yang dibutuhkan oleh contoh dijadikan $\mathrm{ml} \mathrm{0,1000} \mathrm{N}$ untuk kemudian dalam 


\begin{tabular}{|c|c|c|}
\hline JURNAL PENELITIAN FARMASI HERBAL & VOL. 1 NO. 2 & $\begin{array}{c}\text { EDITION: NOVEMBER 2018 } \\
\text { APRIL 2019 }\end{array}$ \\
\hline & http://ejournal.delihusada.ac.id/index.php/JPFH & \\
\cline { 2 - 2 } RECEIVED: 17 FEBRUARI 2019 & REVISED: 18 MARET 2019 & ACCEPTED: 21 APRIL 2019 \\
\hline
\end{tabular}

tabel luff schoorldicari berapa $\mathrm{mg}$ glukosa yang tertera untuk $\mathrm{ml}$ tio yang dipergunakan.

Rumus Penetapan Gula Menurut Luff Schoorl sebagai berikut:

$\%$ Gula sebelum inversi $=\frac{W 1 \times F P}{w} \times 100 \%$ (1)

Keterangan:

$\mathrm{W}_{1}=\mathrm{mg}$ Glukosa (dari tabel Luff Schoorl)

$\mathrm{FP}=$ Faktor pengenceran $(\mathrm{ml})$

$\mathrm{w}=$ Bobot Contoh $(\mathrm{mg})$

$\%$ Gula setelah inversi $=\frac{W 2 \times F P}{w} \times 100 \%$ (2)

Keterangan:

$\mathrm{W}_{2}=\mathrm{mg}$ Glukosa (dari tabel Luff Schoorl)

$\mathrm{FP}=$ Faktor pengenceran $(\mathrm{ml})$

$\mathrm{W}=$ Bobot Contoh $(\mathrm{mg})$

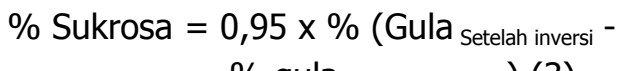

$\%$ gula sebelum inversi) (3)

(SNI 01-2892-1992)

\section{HASIL DAN PEMBAHASAN}

Pada percobaan penetapan kadar glukosa dan sukrosa dalam madu hutan dengan menggunakan metode Luff Schoorl, diketahui glukosa dan sukrosa yang terkandung didalam madu hutan memenuhi syarat sesuai dengan SNI 01-3545-2013 yaitu glukosa minimal 65\% dan sukrosa maksimal 5\%. Kadar rata-rata glukosa dapat dilihat pada tabel 2 dan kadar rata-rata sukrosa dapat dilihat pada tabel 3 .

Tabel 2. Hasil Penetapan Kadar Glukosa Pada Madu Hutan

\begin{tabular}{|c|c|c|c|c|}
\hline No & Sampel & $\begin{array}{c}\text { Berat } \\
\text { Sampel } \\
(\mathrm{g})\end{array}$ & $\begin{array}{c}\text { Kadar } \\
\text { Glukosa } \\
\%\end{array}$ & $\begin{array}{c}\text { Kadar } \\
\text { Rata- } \\
\text { rata }\end{array}$ \\
\hline 1 & & 1.2652 & 71.47 & \\
2 & $\mathrm{~A}$ & 1.3542 & 71.29 & 71,42 \\
3 & & 1.3988 & 71.49 & \\
\hline 1 & & 1.1146 & 66.18 & \\
2 & $\mathrm{~B}$ & 1.2089 & 66.52 & 66,24 \\
3 & & 1.1731 & 66.03 & \\
\hline 1 & & 1.3284 & 71.24 & \\
2 & $\mathrm{C}$ & 1.4427 & 71.16 & 71,21 \\
3 & & 1.4041 & 71.22 & \\
\hline
\end{tabular}

Tabel 3. Hasil Penetapan Kadar Sukrosa Pada Madu Hutan

\begin{tabular}{|c|c|c|c|c|}
\hline No & Sampel & $\begin{array}{c}\text { Berat } \\
\text { Sampel } \\
(\mathrm{g})\end{array}$ & $\begin{array}{c}\text { Kadar } \\
\text { Sukrosa } \\
\%\end{array}$ & $\begin{array}{c}\text { Kadar } \\
\text { Rata- } \\
\text { rata }\end{array}$ \\
\hline 1 & \multirow{3}{*}{ A } & 1.2652 & 3.10 & \multirow{3}{*}{3,09} \\
\hline 2 & & 1.3542 & 3.10 & \\
\hline 3 & & 1.3988 & 3.06 & \\
\hline 1 & \multirow{3}{*}{ B } & 1.1146 & 4.50 & \multirow{3}{*}{4,51} \\
\hline 2 & & 1.2089 & 4.51 & \\
\hline 3 & & 1.1731 & 4.51 & \\
\hline 1 & \multirow{3}{*}{ C } & 1.3284 & 3.01 & \multirow{3}{*}{3,04} \\
\hline 2 & & 1.4427 & 3.06 & \\
\hline 3 & & 1.4041 & 3.06 & \\
\hline
\end{tabular}

Keterangan:

Sampel A berasal dari madu hutan dari Desa Kubu Simbelang

Sampel B berasal dari madu hutan dari Desa Bunuraya

Sampel $\mathrm{C}$ berasal dari madu hutan dari Desa Suka

Dari hasil penelitian diketahui bahwa kadar rata-rata glukosa pada madu hutan sampel Asebesar 71,42\%, Sampel B 66,24\%, Sampel C $71.21 \%$ dengan ini membuktikan bahwa Kadar Glukosa pada ketiga sampel Madu Hutan tersebut masing-masing sesuai dengan SNI 01-3545-2013, yaitu minimal 65\%. Sedangkan kadar rata-rata sukrosa pada sampel A sebesar 3,09\%, Sampel B 4.51\%, dan Sampel C 3.04\% yang berarti Kadar Sukrosa sesuai dengan SNI 01-3545-2013 yaitu maksimal $5 \%$.

Prinsip dasar pada analisa yang digunakan adalah Iodometri yaitu proses titrasi terhadap iodium dalam larutan. Dalam hal ini, CuO dalam larutan Luff akan direduksi oleh monosakarida menjadi $\mathrm{Cu}_{2} \mathrm{O}$. Kelebihan $\mathrm{CuO}$ yang terdapat dalam larutan akan direduksi dengan $\mathrm{KI}$ sehingga dilepaskan $\mathrm{I}_{2}$ yang jumlahnya setara dengan jumlah $\mathrm{CuO} . \mathrm{I}_{2}$ yang terdapat dalam larutan kemudian dititrasi dengan larutan $\mathrm{Na}_{2} \mathrm{~S}_{2} \mathrm{O}_{3}$ dengan penambahan indikator amilum sehingga terbentuk kompleks iod-amilum. Titik akhir titrasi ditandai dengan perubahan warna larutan dari biru menjadi putih. 
Selisih volume $\mathrm{Na}_{2} \mathrm{SO}_{3}$ yang digunakan pada titrasi blanko dan sampel selanjutnya dikonsultasikan terhadap tabel luff schoorl sehingga diperoleh $\mathrm{mg}$ glukosa dalam sampel, lalu dimasukkan kedalam perhitungan untuk menentukan kadar glukosa pada sampel.

Glukosa merupakan monosakarida yang merupakan gula pereduksi, sehingga penentuannya dengan metode luff school dapat langsung dilakukan. Sementara untuk sukrosa memerlukan tahapan hidrolisis terlebih dahulu sebelum dilakukan penetapan dengan metode Luff Scoorl. Sukrosa berbeda dengan disakarida yang lain dalam hal daya reduksinya. Sukrosa tidak mempunyai daya mereduksi sama sekali, karena gugus pereduksi kedua satuan itu ikat-mengikat. Terdiri dari glukosa dan fruktosa. Ikatannya adalah 1,2-glukosidik (Iswari, R.2006).

Untuk penentuan kadar sukrosa perlu dilakukan hidrolisis terlebih dahulu. Hidrolisis sukrosa juga dikenal sebagai inversi sukrosa. Hasil hidrolisis sukrosa berupa campuran unitunit mono sakarida penyusunnya yaitu glukosa dan fruktosa. Glukosa dan fruktosa dari hasil hidrolisis sukrosa ini disebut juga gula invert. Inversi dapat dilakukan baik dengan memanaskan sukrosa bersama asam atau dengan menambahkan enzim intervase (Gaman, 1981).

Pada penelitian ini, hidrolisis sukrosa dilakukan dengan penambahan asam klorida. Hasil hidrolisis ini selanjutnya diberi perlakuan yang sama dengan penetapan glukosa sebelumnya. Menurut Verhaart dalam Winarno (1981), tingkat kesalahan pengukuran kadar gula dengan metode Luff Schoorl adalah sebesar $10 \%$ dan metode ini merupakan metode terbaik untuk mengukur kadar karbohidrat.

Ada berbagai faktor yang mempengaruhi mutu madu, diantaranya adalah Jenis Bunga karena bunga sebagai sumber nektar, Penyimpanan, Pemanasan, Kadar air, Suhu dan Cuaca (Winarno, 1981). Dari ketiga madu yang diteliti, ketiganya memiliki kadar glukosa dan sukrosa yang berbeda-beda. Menurut Rosita (2007), tinggi rendahnya glukosa pada madu salah satunya dipengaruhi oleh kondisinektar dimana pada musim kemarau bunga tumbuh-tumbuhan memiliki kadar air rendah sehingga mengakibatkan kadar glukosa pada madu yang dihasilkan juga menurun. Peranan glukosa dalam madu adalah sebagai pemberi rasa manis dan tingkat kemanisannya lebih tinggi dibandingkan dengan gula.

Rasa manismadu juga beragam. Ada madu yang rasanya manis tulen,manis agak asam, manis wangi dan ada juga manis kepahitpahitan. Semua itu merupakan hasil produksi lebah sesuai dengan apa yang dikonsumsinya (Masun, 2005).

\section{KESIMPULAN}

Dari penelitian diperoleh kadar rata-rata glukosa untuk sampel $A$, $B$ dan $C$ berturutturut adalah $71,42 \%, 66,24 \%$, dan $71.21 \%$ sedangkan kadar rata-rata sukrosa untuk sampel A, B dan C berturut-turut adalah $3,09 \%$, 4.51\%, dan 3.04\%. Kadar glukosa dan sukrosa pada ketiga madu hutan yang diteliti memenuhi syarat SNI 01-3545-2013 yaitu glukosa minimal $65 \%$ dan sukrosa maksimal $5 \%$.

\section{DAFTAR PUSTAKA}

Badan Standarisasi Nasional. (1992). Cara Uji Gula SNI 01-2892-1992. Jakarta: Badan Standardisasi Nasional

Badan Standarisasi Nasional. (2014). Madu SNI 01-3545-2013. Jakarta: Badan Standardisasi Nasional.

Dharmestiwi, K.I., (2007). Perkembangan Produksi Madu Lebah Hutan (Apis dorsata) Di Kawasan Gunung Tampomas Utara, Kabupaten Sumedang. Skripsi. Institut Pertanian Bogor

Gaman,P., dan Sherrington,K. (1981). Ilmu Pangan, Pengantar Ilmu Pangan, Nutrisi, dan Mikrobiologi. Yogyakarta: Gadjah Mada University Press Halaman 59-64 


\begin{tabular}{c|c|c}
\hline JURNAL PENELITIAN FARMASI HERBAL & VOL. 1 NO. 2 & $\begin{array}{c}\text { EDITION: NOVEMBER 2018 - } \\
\text { APRIL 2019 }\end{array}$ \\
\hline & http://ejournal.delihusada.ac.id/index.php/JPFH & \\
\cline { 2 - 3 } RECEIVED: 17 FEBRUARI 2019 & REVISED: 18 MARET 2019 & ACCEPTED: 21 APRIL 2019 \\
\hline
\end{tabular}

Iswari, R dan Yuniastuti, A. (2006). Biokimia. Yogyakarta:Graha ilmu Halaman 16

Kementrian Kesehatan Republik Indonesia. (2014). Farmakope Indonesia edisi V. Kementrian Kesehatan RI. Jakarta.

Masun, MS. (2005). Jeli Memilih Madu. Adicitia.Yogyakarta.

Rosita. (2007). Berkat Madu Sehat, Cantik, dan Penuh Vitalitas.Qanita. Bandung.

Sarwono, B. (2001). Lebah Madu. Jakarta: Agromedia Pustaka. Halaman 61-63.
Sihombing, D.T.H. (1997). Ilmu Ternak Lebah Madu. Yogyakarta: Gadjah Mada University Press. Halaman 35; 100-102.

Sudarmadji. (1996). Analisa Bahan Makanan dan Pertanian. Yogyakarta: Liberty Yogyakarta. Halaman 80-81.

Sumoprastowo dan Agus S. (1993). Beternak Lebah Madu Modern. Jakarta: Penerbit Bhratara. Halaman 54.

Winarno, F.G. (1981). Madu Teknologi, Khasiat dan Analisa. Bogor: Pusbangtepa. Halaman 25-26 